\title{
Arbeitsökonomik
}

von

\author{
Jürgen Zerche
}

mit einem Beitrag von Fritz Gründger

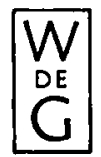

1979

Walter de Gruyter · Berlin · New York 
Dipl.-Volkswirt Dr. rer. pol. Jürgen Zerche

o. Professor für Sozialpolitik an der Wirtschafts- und Sozialwissenschaftlichen Fakultät der Universität zu Köln

Dipl.-Volkswirt Dr. rer. pol. Fritz Gründger

Professor an der Evangelischen Fachhochschule Berlin

CIP-Kurztitelaufnabme der Deutschen Bibliothek

\section{Zerche, Jürgen}

Arbeitsökonomik / von Jürgen Zerche. Mit einem Beitrag von

Fritz Gründger. - Berlin, New York: de Gruyter, 1979.

(Sammlung Göschen; 2006)

ISBN 3-11-006847-8

(C) Copyright 1979 by Walter de Gruyter \& Co., vormals G. J. Göschen'sche Verlagshandlung, J. Guttentag, Verlagsbuchhandlung, Georg Reimer, Karl J. Trübner, Veit \& Comp., 1000 Berlin 30Alle Rechte, insbesondere das Recht der Vervielfältigung und Verbreitung sowic der Übersetzung, vorbehalten. Kein Teil des Werkes darf in irgendeiner Form (durch Fotokopie, Mikrofilm oder ein anderes Verfahren) ohne schriftliche Genehmigung des Verlages reproduziert oder unter Verwendung elektronischer Systeme verarbeitet, vervielfältigt oder verbreitet werden - Printed in Germany - Satz und Druck: Kupijai \& Prochnow, 1000 Berlin 61 -, Bindearbeiten: Lüderitz \& Bauer, Buchgewerbe-GmbH, 1000 Berlin 61 